\title{
Global Interest Rate Environment with Emphasis on Quantitative Easing Implications
}

\author{
Emmanuel Teitey \\ Research Department, Noble International Business /Doctoral School, Accra, Ghana
}

Email address:

Teitey2000@yahoo.com,eminet1972@hotmail.com

To cite this article:

Emmanuel Teitey. Global Interest Rate Environment with Emphasis on Quantitative Easing Implications. American Journal of BioScience. Vol. 5, No. 4, 2017, pp. 59-63. doi: 10.11648/j.ajbio.20170504.11

Received: March 2, 2017; Accepted: March 24, 2017; Published: June 1, 2017

\begin{abstract}
Constructing global real interest rates at short and long maturities and reviews their evolution since 1980. It also traces the evolution of the cost of capital, It then analyzed key factors that could explained the observed pattern, shift in savings, changes in monetary and fiscal policy, shift in investment demand, changes in relative prices of investment, monetary policy and portfolio shifts between bonds and equity. It closes by considering how the main factors behind the decline in real interest rates might play out in the medium term. Real interest rates and the cost of capital are likely to rise moderately in the medium term from current level. Part of the reason is cyclical, the extremely low real interest rates of recent years reflects large negative output gaps in advanced economies. Indeed, the real interest rates might have declined even further in the absence of the zero lower bound on nominal interest rate.
\end{abstract}

Keywords: Real, Interest, Nominal, Monetary, Fiscal

\section{Introduction: Global Interest Rate Environment with Emphasis on Quantitative Easing Implications}

Financial crises are often associated with deep seated changes in both the mandates and functions of central banks. This is a well-established regulation in contemporary economic history. For example, central banks inaction was widely held responsible for worsening the economic downturn during the great depressions of the 1930s. The result was that monetary policy was placed under the control of fiscal authority for nearly two decades afterwards. The great inflation of the $1970 \mathrm{~s}$ had the opposite effect. The failure of weak monetary regimes to reign in high inflation led to the establishment in the early $1980 \mathrm{~s}$, of monetary policy frameworks solidly anchored by price stability mandates and safeguarded by independent and autonomous central banks. Some aspect of the framework in most view, will undoubtedly survive the crises. One is the great and increasing shared emphasis on central bank independence. Another is the central of price stability for monetary policy. These were the twin foundations of the dominant monetary policy paradigm before the crisis and the crisis has not challenged or discredits either of them.

In summary, the demand for safe assets increased, largely reflecting the rapid reserve accumulation in some emerging market economies and increases in the riskiness of equity relative to bonds. Third, there has been a sharp and persistent decline in investment rates in advanced economies since the global financial crisis. This paper argues that global interest rates can be expected to rise in the medium term but only moderately, since these three factors are unlikely to reverse substantially. The zero lower bound on nominal interest rates will remain a concern for same time; the real interest rates will likely remain low enough for the zero lower bound to reemerge should risks of very low growth in advanced economies materialize. In the past few years, many borrowers with good credit rating have enjoyed a cost of debt close to zero or even negative when it is adjusted for inflation. This is not just a consequence of the global financial crisis. Since the early 1980s, yields of all maturities have declined worldwide well beyond the decline in inflation.

However, because the recent interest rate declines reflects to a large extent weak economic condition in advance economies after the crisis, some reversal is likely as these 
economies return to a more normal state. But how much of a reversal? Certain factors suggest a substantial increase in interest rates in the medium term, high and rising debt levels in advanced economies, population aging, lower growth in emerging market economies which might lower their saving rates and further financial deepen in emerging market economies which would reduce borrowing constraints and thereby net saving. Other factors, however, would work in the opposite direction, long lasting negative effect of the global financial crisis on economic activity (Cerra \& Saxena, 2008; Reinharrt \& Rogoff, 2008) persistence of the "saving glut" in key emerging market economies and renewed declines in the relative prices of investment.

\section{Research Framework and Methodology}

Data on Real interest rate was collected from Secondary sources like Articles, Journals, Empirical literatures, Textbooks and Internet sources for analysis on Global interest rates environment with emphasis on Quantitative Easing implication. Qualitative methodology was applied for this research paper. Descriptive research design and analysis on the global interest rate environment with emphasis on quantitative Easing implication were employed to investigate the global interest behavioral. For the purpose of analysis, a secondary data was used to analyze the various literatures on global interest rate with emphasis on quantitative easing implication.

The researcher obtained both primary and secondary data from the various case studies for the analysis of the global interest rates. The primary data was in the form of interviews with the concern officials. Secondary data was in the form of documents obtained from the internet, literatures reviewed and other articles for the analysis of the quantitative easing implication.

\section{Research Framework}

The turmoil in global financial assets markets following the by Bernanke (2012) the Federal Reserve's Quantitative Easing ( or Large Scale Assets Purchases ) program may be slowed has raised further questions about the effectiveness of such so called unconventional monetary policy pursued by central banks to deal with the North Atlantic Financial Crisis of 2007-09 and resulting global downturn. One implication of this markets volatility is that QE may artificially inflate financial assets prices with resulting temporal confidence effects but make little difference to macroeconomic fundamentals. Unfortunately, much of the existing literature on $\mathrm{QE}$ does not specifically examine the impact of QE on key broader macroeconomic variables, such as real interest rates, nominal demand, GDP growth and inflation. This is despite the fact that some central banks include the Bank of England made it clear that these were the ultimate goals of the policy.
In this regard, the approach chosen by the European Central Bank and the Eurosystem differ from that of other major central banks which embarked on large-scale unconventional measures to replace, rather than complement standard actions, after those standard actions changes in the policy interest rate had reached their lower limit. Furthermore, the ECB's non-standard response does not qualify as a form of quantitative easing or credit easing. Nonstandard monetary policy measures are an extraordinary response to exceptional circumstance. They are by construction temporary in nature. Looking ahead to return to more normal liquidity management and to a more moderate scale of central bank intermediations are warranted to avoid distortions in financial incentives with longer-term adverse consequences for the economy. The ECB started to phase out a number of non-standard measures back in late 2009 .

The maintenance of price stability over the medium term guides all monetary policy decisions. Again, the macroeconomic and financial landscape has fundamentally changed and the monetary policy stance has become more accommodative that at the peak of the crisis. The scenario of phasing in of non-standard measures, there are no predefined steps between phasing them out and existing from very low policy interest rates. The ECB will adjust its policy interest rates and its provision of liquidity at a pace and to a degree commensurate with the evolution of risk to price stability and as appropriate to maintain an orderly and functional monetary policy transmission.

In January 2013, the Bank of Japan introduced an inflation target of $2 \%$ followed by quantitative and qualitative monetary Easing (QQE) in April 2013.These measures aim at establishing more accommodative condition, even at the zero lower bound of short-term nominal interest rates, by increasing inflation expectation and lowering real interest rate which in turn should end chronic deflation. The objective is to manage expectation. According to Eggertssion and Woodford (2003) academic literature, inducing a policy regime change by managing expectations can stop virulent inflation or deflation. The unconventional monetary policy (QQE) aims at easing a monetary policy under the zero lower bound of nominal interest rates by controlling the inflation expectations of the private sector. Thus, the success of QQE ending chronic deflation depends on the feasibility of management of expectation.

Capistran and Timmermann (2009) documented crosssectional dispersion among forecasters using U.S. data. Dovern, Fritsch, and Slacalek (2009) discuss disagreements forecasted in G7 countries while the literature reports crosssectional disagreement among forecasters. It is possible cross-sectional dispersion poses as an obstacle in implementing an unconventional monetary policy through management expectation. Another aspect of disagreement is whether long-run inflation forecasts converge to the $2 \%$ target set by the Bank of Japan to achieve price stability. The bank of Japan is committed to achieving this target over a 2year period starting from April 2013.If this commitment is fully credible and becomes widespread, long-term inflation 
forecasts by agents will immediately converge to the $2 \%$ level. Otherwise, any dissonance among the central bank and agents can hinder attempts to end chronic deflation in Japan.

\section{Main Findings of the Study}

The empirical data analysis from the primary, secondary sources and the other literature reviewed sources has shown that global interest rate environment with emphasis on Quantitative Easing implication and others were possible due to the results from the study enumerated as below:

A few years after the financial crisis most advanced economies have sought to so many monetary policy decisions (Quantitative Easing) so as to reduce interest rates and inflation. These brought about the recent interest rates declines and to large extent weak economic conditions in the advance economies like France, Germany, United Kingdom and United State. However, certain macroeconomic factors suggest an increases interest rate in the medium term, high and rising debts levels in advanced economies and lower growth in emerging market economies which might lower their saving rates. This scenario could be depicted from Table 1 .

Table 1. Current and Expected Interest Rates.

\begin{tabular}{lll}
\hline Central Bank & Interest rate & Interest rate \\
\hline Current & Expected & \\
Federal Reserve System & $0.15 \%$ & $0.25 \%$ \\
European Central Bank & $0.00 \%$ & $0.00 \%$ \\
Bank of Japan & $-0.1 \%$ & $-0.1 \%$ \\
Bank of Ghana & $26 \%$ & $26 \%$ \\
\hline
\end{tabular}

A quick look at figures in Table 1, one could analyzed that the Federal Reserve rate stood at an average of $0.15 \%$ and expected increase is about $0.25 \%$ which has some positive effect in the economy and downward turn in the emerging market economies as well as lowering their saving rates. The European Central bank interest rate was at lower of zero percent and still remains unchanged which is an indication of weak investment and excess savings. The low interest rate supports consumption and jobs benefit which are always said to be social progressive in nature. However, the lower rates also benefit investors and wealthy people who traded in stock and other Assets because their activities have been boosted by the lower interest rate.

The Bank of Japan has also left its negative interest rate at $-0.1 \%$ percentage unchanged as it has being depicted in the Table1.This is an effort by the Central bank to keep the economy from sliding back into the stagnation that has dogged it for much of the last two decades. The negative interest rate shows a damage cycle of price falls and weakens economy. The Bank of Japan had it that the negative interest rate is a move towards the introduction of yield curve control to hasten its struggle against deflation. The bank of Ghana has its current interest rate at $26 \%$ percent and will remain unchanged for a while. This has given the indication that Bank of Ghana has worst policy rate in the world if not the last. The policy rate of $26 \%$ would make cost of borrowing very an expensive which will lead low saving and low investment hence low production. Basically that is the type of economy that Ghana is confronted with but serves as an advantage to the investors in stock and other assets. Table1 can be presented diagrammatically as below:

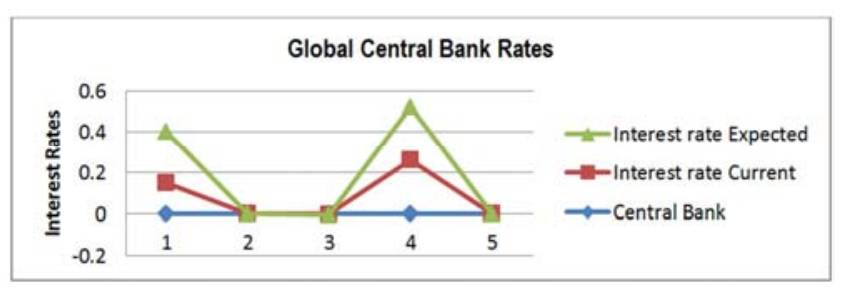

Figure 1. Central Bank Interest Rate.

\section{General Impact of Global Interest Rate Environment}

The level of interest rate in one economy matters a lot, main because of it is redistributive, Borrowers gain at the expense of savers and savers include all those who depend on their savings for their daily incomes, especially retired people. For the whole financial industry, the interest rate is the most important variable with extraordinarily wide effect, including on shares prices and risk-taking which puts taxpayers at risk. The interest rate also affects the exchange rate and therefore income distribution between exportoriented firms, their employees and consumers. The remarkable aspect of the current experience is that the policy interest rate has been brought down to very close to zero, the normal lower bound.

However, what matters for the macro economy is the interest rate at longer maturities which better reflects the borrowing cost by consumers and firms. The real interest rates for four major developed countries like Germany, Japan, United Kingdom and United State observe a secular decrease which accelerated after 2007 when the global financial crisis was under way. By 2012, the real interest rates are about zero in three out of the four countries which has not been seen for over 30years. The impact will also be assessed and analysed using the following Table.

Table 2. Impact of the Global interest rate on Equity/Stock Prices/Valuation.

\begin{tabular}{llll}
\hline Central Bank & Equity & Stock Prices & Valuation \\
\hline Federal Reserve System & $\uparrow$ & $\uparrow$ & $\uparrow$ \\
European Central Bank & $\uparrow$ & $\uparrow$ & $\uparrow$ \\
Bank of Japan & $\uparrow$ & $\uparrow$ & $\uparrow$ \\
Bank of Ghana & $\downarrow$ & $\downarrow$ & $\downarrow$ \\
\hline
\end{tabular}

The assessment of the impact of global interest rate on macroeconomic could be clearly analysis from the table 2.The arrow for equity capital in all the three advance economies has showed upward indicating an increase equity investment due to the unchanged low interest in this economy. Investors have moved from fixed income securities like bonds which have gain low returns due to lower interest rate towards stocks and more generally towards more risk taking while the arrow for Ghana descended downwards 
indicating decrease in equity capital patronage due to high interest rate of $26 \%$ confronted by the Ghanaian economic. This is a signal that fixed income securities are made more attractive in this sense. A regime of low interest rates also strengthens stock or share prices and this is main reason why the stock prices arrow pointed upward also indicating increases in stock prices in all the three advance economies and Ghana pointed downwards suggesting reduction in stock prices and making equity investment less attractive.

The valuation in stock could be depicted from Table2.The arrows in this circumstances have all depicted upward movement which was the reflection of the appreciation in stock but there are some situation in low interest rate economy whereby this result shows fluctuation rather than appreciation and here again Ghana had declined in valuation due to $26 \%$ higher interest rate. The fluctuation low interest rate economy could be seen from S\&P 500 earning yield in figure 2 .

Clearly, changes in the federal funds rate affect the behaviors of consumers and business but the stock market is also affected. Remember that one method of valuing a company is to take the sum of all the expected future cash flows from that company discounted back to the present. To arrive at a stock's price, take the sum of the future discounted cash flow and divide it by the number of shares available. This price fluctuates as a result of the different expectations that people have about the economy at difference interest rate and earnings yields. S\&P earning yield below is a typical example:

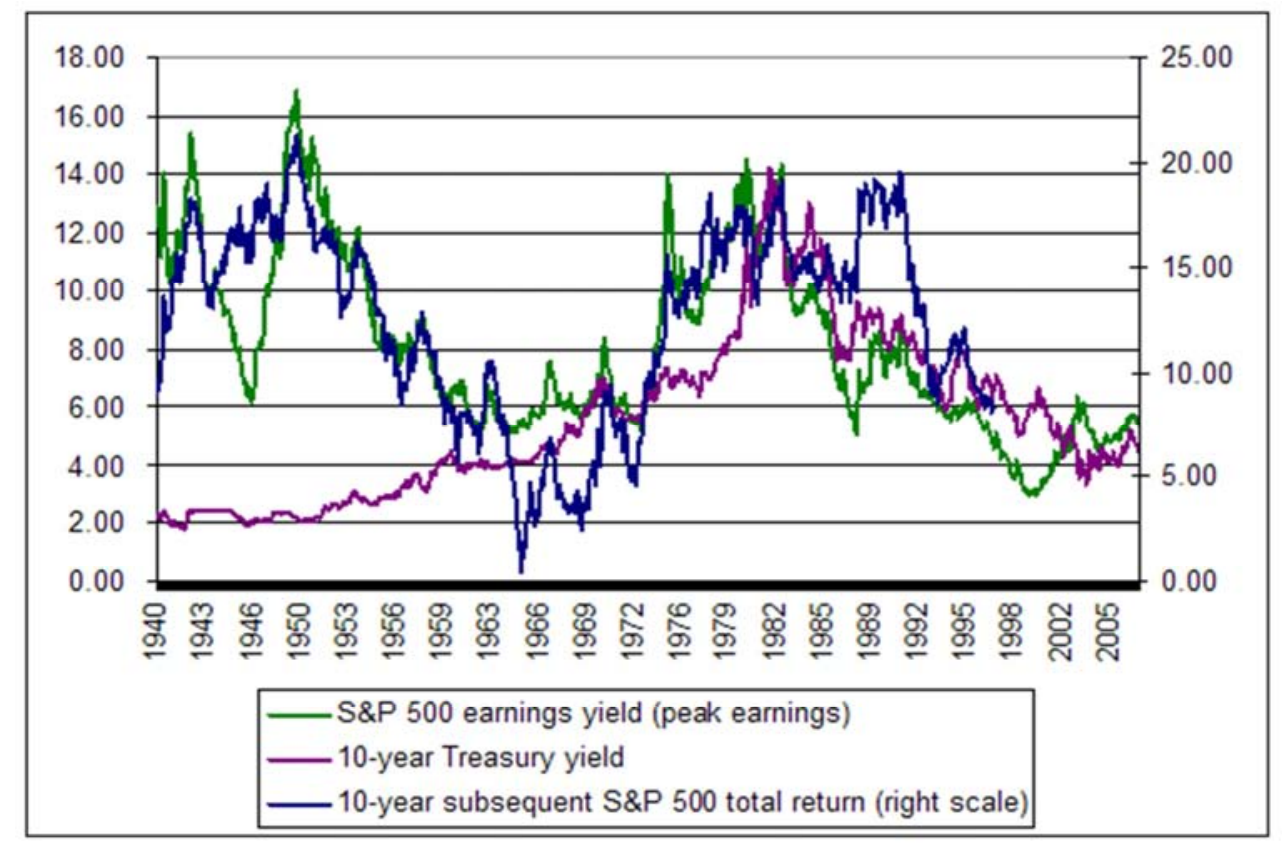

Figure 2. Source S\&P 500 earning yield curves.

\section{The Comparative Interest Rate between Ghana and Neighboring Countries}

Analysis could also be than among Ghana and the neighboring countries so to assess their current interest rate and inflation and the impact of this macroeconomic variable in the home country.

Table 3. Countries Specific Interest Rate and inflation Compares.

\begin{tabular}{lll}
\hline Country & Interest Rate & Inflation \\
\hline Ghana & $26 \%$ & $17.20 \%$ \\
Togo & $3.50 \%$ & $-0.90 \%$ \\
Cote D'lvoire & $3.50 \%$ & $0.70 \%$ \\
Burkina Faso & $3.50 \%$ & $-0.60 \%$ \\
Nigeria & $14 \%$ & $17.90 \%$ \\
\hline
\end{tabular}

At glance from Table 3 one could clearly examine that the Franphone West Africa countries have lower interest rate as well as lower inflation rate which is an indication of good economic condition at the home countries but that was not the case in reality. Togo with interest rate as low as $3.50 \%$ and inflation rate as $-0.90 \%$ has not shown any sound economic trend in terms of trade and investment condition compares to Ghana and Nigeria in the sub-region. Even, though with their free port trading condition has not promoted trade and investment in the sub-regional to any level. Cote D'Ivoire also has low interest rate of $3.50 \%$ and inflation $0.70 \%$ could have been on top of economic issues in the sub-regional but due to political instability, issues concerning trade and investment they have lack a lot in the sub-regional, however, their economy is receiving substantial growth in terms production, agriculture, trade and investment.

Burkina Faso has shown a good interest rate and inflation rate as low as $3.50 \%$ and $-0.60 \%$ but when we talk about trade and investment in the sub-regional their contribution was very less and one would wonder whether these figures 
are really transferring into reality. However, Ghana and Nigeria depicted higher interest rate and inflation rate on the list of the table, their seen as the giant in the sub-regional in terms of economic stability, trade and investment. The interplay among these countries is that they trade and do business in the sub-regional and the effect of one interest rate and inflation rate affect the other. Their interest rates and inflation rates could be assessing from figure 3 .

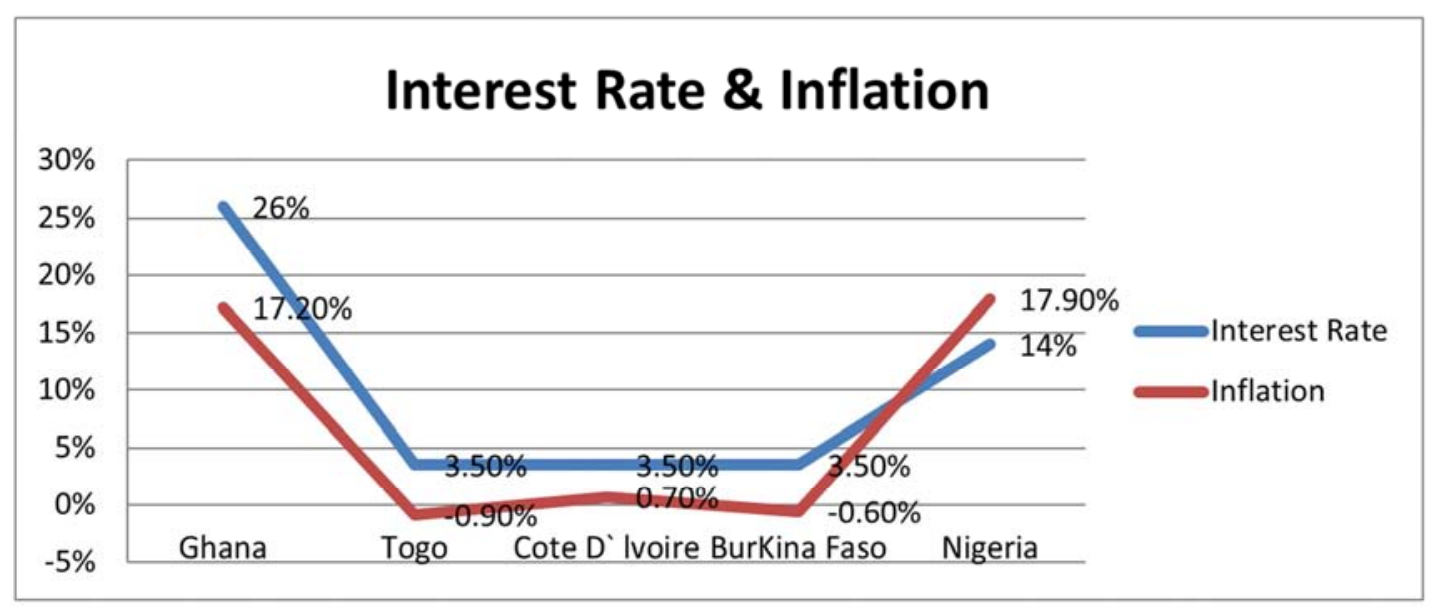

Figure 3. Interest rate and Inflation rate for Ghana and neighboring countries.

\section{Discussion the Implication of the Study}

The real interest rate which matters for the macroeconomic effect of monetary policy is about zero in some countries but not very low in others, especially in the euro area crisis countries. Thus monetary policy is not universally accommodative.

If it lasts, a very low nominal short-term rate can disrupt financial markets by encouraging investment to increase risk taking and promoting the emergence of asset prices bubbles, in several countries prices appear very high.

Finally, if raising interest rate has so many negative effects on consumption, investment, government spending and net export, why undertake such a policy? The answer is that as the economy recovers and reaches full employment, low interest rate could lead to excess demand or an overheated economy and an outbreak of inflation.

\section{Conclusion}

Adopting the approach of Vousinas and Werner (2016), and building on Lyonnet and Werner's(2012) study of UK QE, this paper addresses these weaknesses by examining the impact of various different monetary policy instrument, including quantitative easing directly on UK and other advance economies nominal GDP growth.

Macroeconomic valuables have significant effect in many economies, if the monetary policy are not control, particularly, the market volatility is more sensitive to changes in interest rate and other economic valuables (Harlina, Intan, Nasruddin, \& Emi, 2011).This translate, therefore, into higher interest rates offered to customers of banks and other financial institute who contract credit, hence, low prices of stock and shares, especially in the developing economies leading to high
inflation(Zenith Bank Ghana, Ltd,2015).

\section{References}

[1] Bernanke, B., (2012).The Federal Reserve's quantitative easing or large scale assets purchase program. www.thedaily economist.com/2012/_09_01 archive.html. Retrieved: October $28^{\text {th }} 2016$

[2] Capistran, C., \& Timmermann, A. (2009). Disagreement and biases in inflation expectation. Journal of Money, Credit and banking, (41)366-396.

[3] Cerra,V., \& Saxena, S. C. (2008).Growth dynamics: The myth of economic recovery, American Economic Review. 98(1)43957.

[4] Dovern, J., Fritsch, U., \& Slacalek, J. (2009). Disagreement among Forecaster in G7 countries, ECB workingpaper 1082.

[5] Eggertsson, G. B., \& Woodford, M. (2003). The zero bound on interest rates and optional monetary policy. Brooking Paper on Economic Activity. (1)139-211.

[6] Harlina, S. J., Intan, R. E., Nasruddin, F., \& Emi, N. O. (2011). The economic growth and how effectiveness is the stock market. International Business Journal, 24(6)24-25.

[7] Lyonnet, V., \& Werner, R. A. (2012). Lessons from the Bank of Ghana on quantitative easing and the accountability of the central bank in Japan. Working paper presented at the $15^{\text {th }}$ annual meeting of the annual international conference on macroeconomic analysis and international finance.

[8] Reinharrt, C. M., \& Rogoff, K. S., (2008). Is the U. S. subprime crisis so different? An international historical comparison. Americal Economic Review. 98 (2)339-44.

[9] Voutsinas, Y., \& Werner, R. A.,(2016).Bank runs, deposit instruments and Liquidity. Journal of Political Economy,(2) 2635 .

[10] Zenith Bank (Ghana) Ltd. (2015a). Z-Business news, Monthly Bulletin, January (100), 2-3. 